\title{
BIOSTIMULATION OF AGRICULTURAL BIOBEDS WITH NPK FERTILIZER ON CHLORPYRIFOS DEGRADATION TO AVOID SOIL AND WATER CONTAMINATION
}

\author{
G.R. Tortella ${ }^{1}$, O. Rubilar ${ }^{1}$, M. Cea ${ }^{1}$, C. Wulff ${ }^{1}$, O. Martínez ${ }^{1}$, and \\ M.C. Diez ${ }^{1,2}$ \\ ${ }^{1}$ Scientific and Technological Bioresource Nucleus, Universidad de La Frontera, PO Box 54-D \\ Temuco, Chile. ${ }^{2}$ Chemical Engineering Department, Universidad de La Frontera, PO Box 54-D \\ Temuco, Chile. *Corresponding author: gtortell@ufro.cl
}

\begin{abstract}
Degradation of the insecticide chlorpyrifos (160 a.i mg kg-1) using a biomix of a biobed system biostimulated with inorganic fertilizer (NPK) was investigated. Three concentrations of the fertilizer $\left(0.1 \%, 0.5 \%\right.$ and $\left.1.0 \% \mathrm{ww}^{-1}\right)$ were evaluated on chlorpyrifos degradation, TCP (3, 5, 6-trichloro-2-pyrinidol) accumulation and biological activity of the biomix. The chlorpyrifos was dissipated efficiently $(>75 \%)$ after 40 days of incubation and no additional dissipation was obtained with increasing concentration of NPK after 20 days of incubation. TCP accumulation occurred in all evaluated NPK concentrations and its concentration increased with the increment of NPK addition raising the probability of leaching of this compound. Biological activity (FDA and ligninolytic enzyme activity) in the biomix increased by the NPK presence in all evaluated concentrations. The DGGE analyses showed that combined treatments with lower amounts of NPK $(0 \%$ and $0.1 \%)$ and chlorpyrifos showed no significant modifications in the microbial community in the biomix. However, combined overdoses of NPK $(0.5$ and $1.0 \%)$ and chlorpyrifos caused significant modifications in the bacterial communities that could be associated with TCP degradation reduction in the biomix. In conclusion, the obtained results demonstrated that the biomix prepared with Andisol and biostimulated with NPK nutrient can be recommended in biobeds as a viable alternative of chlorpyrifos dissipation avoiding soil and water contamination probability.
\end{abstract}

Keywords: Chlorpyrifos, biostimulation, NPK fertilizer, biobed, Andisol

\section{INTRODUCTION}

Pesticides play an important role in the success of modern farming and food production. However, surface and groundwater can be contaminated due to their inadequate management. The release of pesticides into the environment generally occurs by diffuse (nonpoint) or localized (point) sources. Point sources like spillages, tank filling, or cleaning the spraying equipment have been identified as the major risks of contamination of soil and water in agricultural system.

Biobed is a biological technology developed in Sweden and widely used in Europe to minimize point source contamination by pesticides in agricultural system (Torstensson and Castillo, 1997). Typical Swedish biobeds 
are built with simple and cheap materials and a biomix mainly composed of a volumetric proportion of straw $(50 \%)$, peat $(25 \%)$ and soil $(25 \%)$ (Torstensson and Castillo, 1997). Straw is the main component for ligninolytic fungi growth, soil provides sorption capacity and favors microbial activity, and peat contributes to sorption capacity and moisture control in the biomix. Several studies have demonstrated that these biological systems can effectively retain and degrade pesticides including chlorpyrifos (Castillo et al., 2008, Coppola et al., 2007; Vischetti et al., 2008).

Chlorpyrifos $\quad[O, O$-diethyl $O .(3,5,6-$ trichloro-2-pyridyl) phosphorothiate] is a broad-spectrum organophosphorus insecticide widely used throughout the world including in Chilean agriculture. It has a low water solubility $\left(1.39 \mathrm{mg} \mathrm{L}^{-1}\right)$ and a high affinity for soil organic carbon $\left(\mathrm{K}_{\mathrm{oc}}=8498 \mathrm{~mL} \mathrm{~g}^{-1}\right)$ (Racke, 1996). When chlorpyrifos is introduced into the soil it can cause a reduction of soil microbial populations (Chu et al., 2008). In addition, chlorpyrifos bound to soil constituents may be introduced into rivers by surface runoff from agricultural lands (Wu and Laird, 2004). Phillips et al. (2003) reported that this compound bound to suspended colloid is toxic to aquatic organisms.

Pesticide degradation in soil or biobeds can be limited by many factors, for example: soil properties, moisture, temperature, $\mathrm{pH}$ and initial concentration or repeated applications of pesticides (Castillo and Torstensson, 2007; Fogg et al., 2003; Vischetti et al., 2008). Moreover, biostimulation of the indigenous microorganisms by addition of nutrients is an important aspect to be taken into account because the enrichment of the indigenous microbial populations is the most widely tool used in bioremediation procedure. Several works have demonstrated the positive effects of biostimulation, mainly with NPK fertilizers, on contaminant biodegradation in soil (McGhee and Burns, 1995; Margesin and Schinner, 2001; GarcíaBlanco et al., 2007). McGhee and Burns (1995) reported that the addition of a combined NPK fertilizer increased significantly degradation of the herbicides 2,4-D and MCPA. In another work, García-Blanco et al. (2007) determined that fertilization with $\mathrm{N}$ and $\mathrm{P}$ improved oil disappearance in a contaminated site. Similar results were found by Margesin and Schinner (2001), where biostimulation with NPK showed a significant reduction of hydrocarbons in a soil contaminated with diesel, and all biological parameters were also significantly enhanced. Although it has been demonstrated that biostimulation is an effective technique for the treatment of contaminated sites, no information is reported in the literature about the use of biostimulation in a biobed system. Therefore, the objective of our study was to evaluate the effect of the biostimulation with NPK of the biomix of a biobed on the degradation of chlorpyrifos and on the biological parameters of the biomix.

\section{MATERIALS AND METHODS}

\section{Chemicals}

Analytic-grade (99\% purity), chlorpyrifos (O, O-diethyl-O-trichloro-2pyridylphosphorothioate), and TCP (3,5,6-trichloro-2-pyridinol) were purchased from Sigma-Aldrich. Formulated chlorpyrifos (Clorpirifos $\mathrm{S} 480$ ) of $48 \% \mathrm{w} / \mathrm{v}$ was purchased from ASP Chile. MBTH (3-methyl-2benzothiazolinone hydrazone), DMAB (3(dimethylamino) benzoic acid) were purchased from Aldrich. All other 
chemicals and solvents were of analytical reagent grade and were purchased from Equilab and Merck Chile. Commercial NPK fertilizer (20-5-5\%) was purchased from Anasac.

\section{Preparation of biomix and incubation conditions}

The biomix was prepared by mixing an allophanic top soil (Andisol) without chlorpyrifos application history (37.1\% sand, $34.2 \%$ silt, $28.7 \%$ clay), commercial peat-free compost (organic carbon $39.67 \%$ ) and winter wheat straw (organic carbon $43 \%$ ) in the volumetric proportion of 1:1:2, respectively. The biomix (organic carbon $21.16 \%, \mathrm{pH} 6.05$ ) was macerated using a food processor and composted for 15 days at $20 \pm 1^{\circ} \mathrm{C}$ in a polypropylene bag before being used in the experiments. All the materials used for the biomix preparation were passed through a $3 \mathrm{~mm}$ sieve and stored at $4^{\circ} \mathrm{C}$ until use. The chemical analysis of used soil (Andisol) is presented in the Table 1.

Table 1. Characteristics of the Andisol used in this study.

\begin{tabular}{lc}
\hline Parameters & Value \\
\hline Organic carbon (\%) & $8.8 \pm 0.96$ \\
Nitrogen (mg kg $\left.{ }^{-1}\right)$ & $29 \pm 1.52$ \\
Phosphorous Olsen $\left(\mathrm{mg} \mathrm{kg}^{-1}\right)$ & $25 \pm 0.99$ \\
Potassium (mg kg $\left.{ }^{-1}\right)$ & $485 \pm 2.45$ \\
pH (in water) & $6.13 \pm 0.04$ \\
\hline
\end{tabular}

The values are the average of three replicates $(n=3)$.

Available mineral nitrogen $\left(\mathrm{N}-\mathrm{NH}_{4}{ }^{+}+\mathrm{N}\right.$ $\mathrm{NO}_{3}{ }^{-}$) was determined by extraction with $\mathrm{KCl} 2 \mathrm{M}$ and quantification by titration with $\mathrm{HCl}$ and specific electrode, respectively. Available $\mathrm{P}$ was determined by extraction with sodium bicarbonate (0.5 M, pH 8.5) and quantified colorimetrically with the molybdateascorbic acid method.Oración muy larga la cortaría en respectively. $\mathrm{K}$ was quantified by atomic absorption spectrophotometry (Shimadzu GBC SensAA) after extraction with ammonium acetate $1 \mathrm{M}, \mathrm{pH} 7.0$

\section{Effect of NPK on chlorpyrifos degradation}

The biomix samples (25 g) at $60 \%$ of water holding capacity (WHC) were placed in glass flasks $(500 \mathrm{~mL})$ and amended with NPK fertilizer as nutrient source $\left(0.1, \quad 0.5\right.$ and $\left.1 \% \quad \mathrm{~W} \quad \mathrm{w}^{-1}\right)$ Formulated chlorpyrifos (160 mg a.i. $\mathrm{kg}^{-1}$ of biomix) was added to each flask. The chlorpyrifos concentration used in the experiments corresponded to approximately 100 times of field dose. After mixing, the samples were incubated in the dark for 40 days at $20 \pm 1^{\circ} \mathrm{C}$. The biomix moisture level was maintained by the periodic application of distilled water. Biomix samples (from each treatment) were removed at $0,5,10,15,20,30$ and 40 days and stored at $-20^{\circ} \mathrm{C}$ until their analysis. In each sample, residual chloroyrifos, TCP formation, ligninolytic enzymes activity, total microbial activity and microbial community were evaluated. All experiments were made in triplicate.

Chlorpyrifos degradation in biomix was described with the first-order kinetic equation as $\mathrm{C}=\mathrm{C}_{0} \mathrm{e}^{-\mathrm{kt}}$, and from the equation, we obtained (Eq. [1]):

$$
t_{1 / 2}=\operatorname{Ln}(2) / k
$$

Leaching potential of chlorpyrifos was also determined by the GUS index (Groundwater Ubiquity Score) (Eq. [2]) (Gustavson, 1989). This is an important 
index, because it is used for evaluating the potential for groundwater pollution and for leaching of pesticides into surface water via the drainage systems. This index is based on adsorption coefficient $\left(\mathrm{K}_{\mathrm{oc}}\right)$ and half-life $\left(\mathrm{t}_{1 / 2}\right)$ :

$$
G U S=\log _{10}\left(t_{1 / 2}\right) \times\left[4-\log _{10}\left(K_{o c}\right)\right.
$$

\section{Biomix analyses}

Ligninolytic enzyme activity. The analysis was performed using the MBTH/DMAB assay according to the methodology described by Castillo et al. (1994). Briefly, samples (10 g) were weighed into Erlenmeyer flasks and $50 \mathrm{~mL}$ of a 100 $\mathrm{mM}$ succinate-lactate buffer $(\mathrm{pH} 4.5)$ were added to each sample. The flasks were shaken at $100 \mathrm{rpm}$ for $2 \mathrm{~h}$, and 10 $\mathrm{mL}$ of the supernatant were collected and centrifuged at 4,000 rpm for $20 \mathrm{~min}$ and filtered through $0.45 \mu \mathrm{m}$ membrane (National Scientifics filter unit). The reaction mixture contained $300 \mu \mathrm{L}$ of 6.6 mM DMAB, $100 \mu \mathrm{L}$ of $1.4 \mathrm{mM} \mathrm{MBTH}$, $30 \mu \mathrm{L}$ of $20 \mathrm{mM} \mathrm{MnSO}_{4}, 10 \mu \mathrm{L}$ of 10 $\mathrm{mM} \mathrm{H}_{2} \mathrm{O}_{2}$, and $1560 \mu \mathrm{L}$ of the sample in a $100 \mathrm{mM}$ succinic/lactic acid buffer $\mathrm{pH}$ 4.5. The reaction was followed at $590 \mathrm{~nm}$ $\left(\varepsilon=0.053 \mu \mathrm{M}^{-1} \mathrm{~cm}^{-1}\right)$ in a Spectronic Genesis $^{\mathrm{TM}}$ 2PC. As no correction was made for the possible presence of lignin peroxidase (LiP) and laccase (Lac) activity, this measurement may represent the sum of manganese peroxidase, LiP and laccase (Castillo and Torstensson, 2007).

Total microbial activity. The total microbial activity was measured by monitoring fluorescein diacetate hydrolysis (FDA) according to the methodology described by Schnurer and Rosswall (1982) with slight modifications. Briefly, $1 \mathrm{~g}$ of biomix from glass flasks was incubated in a $30 \mathrm{~mL}$ conical flask with $9.9 \mathrm{~mL}$ of sterile 60
$\mathrm{mM}$ sodium phosphate buffer,at $\mathrm{pH}$ 7.8. The reaction was started by adding 0.1 $\mathrm{mL}$ of an FDA solution $\left(2.0 \mathrm{mg} \mathrm{mL} \mathrm{m}^{-1}\right)$. After $1 \mathrm{~h}$ incubation at $25 \pm 1{ }^{\circ} \mathrm{C}, 10 \mathrm{~mL}$ of acetone were added to stop the reaction. $\mathrm{A}_{490}$ was determined after removal of the biomix by centrifugation and filtration. The concentration of the released fluorescein was calculated by a calibration curve with standard quantities of FDA and the results were expressed as $\mu \mathrm{g} \mathrm{FDA} \mathrm{g}^{-1} \mathrm{~h}^{-1}$.

\section{Microbial community analyses}

The microbial community composition in biomix was evaluated at 15 days of incubation after the addition of NPK by DGGE by using specific primer sets for bacteria (Table 2). Briefly, biomix DNA extraction was carried out by using Power Soil DNA Isolation Kit (Mo-Bio Laboratories, Inc., Carlsbad, CA, USA). For bacterial community analysis, fragments of $16 \mathrm{~S}$ rRNA gene were amplified by touchdown polymerase chain reaction (PCR) with the primer set EUBf933-GC/EUBr1387 (454 bp of variable regions $\mathrm{V6}$-V8) (Cea et al., 2010). All PCR amplifications were carried out with reagents supplied with GoTaq ${ }^{\circledR}$ DNA Polymerase (Promega, Co. Madison,WI, USA). DGGE analysis was performed using a DCode system (BioRad Laboratories, Inc.). Twenty microliters of PCR product were loaded onto a $9 \%(\mathrm{w} / \mathrm{v})$ polyacrylamide gel with $20 \%$ and $70 \%$ gradient (urea and formamide). Electrophoresis was run for $16 \mathrm{~h}$ at $100 \mathrm{~V}$. The gel was then stained with SYBR Gold (Molecular Probes, Invitrogen Co.) for 30min and photographed on an UV transilluminator. Modifications in the microbial community composition of each sample were identified through the ImageJ $1.43 \mathrm{u}$ program (Wayne Rasband National Institutes of Health, USA). Clustering 
representation was performed on the data set obtained from DGGE analysis with the software ClustalX.

\section{Pesticide extraction and analysis}

Residual concentration of chlorpyrifos in biomix was determined by HPLC after extraction with $6 \mathrm{ml}$ of acidified acetone (acetone + water + concentrated phosphoric acid, $98+1+1$ by volume) per gram of substrate (Racke et al., 1996). $5 \mathrm{~g}$ (in duplicate) of biomix were mixed with $30 \mathrm{~mL}$ of acidified acetone and incubated under shaking (350 rpm) for $2 \mathrm{~h}$ at $25^{\circ} \mathrm{C}$. Later, the samples were sonicated for $30 \mathrm{~min}$, centrifuged at 10,000 rpm and filtered with PTFS membrane $(0.2 \mu \mathrm{m}$ pore size; Millipore) and then injected in a Merck Hitachi L-7100 pump, a Rheodyne 7725 injector with a $20 \mu \mathrm{L}$ loop and a Merck Hitachi L-7455 diode array detector. The detector was set at 290 $\mathrm{nm}$ and the column was a $\mathrm{C} 18$ column (Superspher RP-C18, $5 \mu \mathrm{m} 4.6$ x 150 $\mathrm{mm})$. The mobile phase consisted of $60 \%$ $\mathrm{CH}_{3} \mathrm{CN}$ and $40 \%$ water/acetic acid $(95.3 / 4.3 \mathrm{v} / \mathrm{v})$ with a flow rate of $1 \mathrm{~mL}$ $\min ^{-1}$ at $25^{\circ} \mathrm{C}$. The chlorpyrifos and TCP recovery was chlorpyrifos and TCP recovery was $>85 \%$. Retention times were $3.7 \mathrm{~min}$ for TCP and $23 \mathrm{~min}$ for chlorpyrifos, detection limits were 0.02 and $0.01 \mathrm{mg} \mathrm{L}^{-1}$ in the aqueous phase for TCP and chlorpyrifos, respectively.

\section{RESULTS AND DISCUSSION}

\section{Effect of NPK on chlorpyrifos degradation}

Chlorpyrifos $\quad\left(160 \quad \mathrm{mg} \quad\right.$ a.i $\left.\quad \mathrm{kg}^{-1}\right)$ degradation in biomix with different NPK doses $(0,0.1,0.5$ and $1 \% \mathrm{w} / \mathrm{w})$ is shown in Figure 1. A high degradation was found in all treatments with NPK. More than $70 \%$ of initial applied chlorpyrifos was dissipated after 40 days of incubation in all treatments. Moreover, an initial rapid dissipation of chlorpyrifos was found during the first 10 days of incubation mainly when 0.1 and $0.5 \%$ of NPK were added to the biomix (Table 2). However, there were no statistically significant differences in the residual chlorpyrifos concentrations in respect to the control after 40 days.

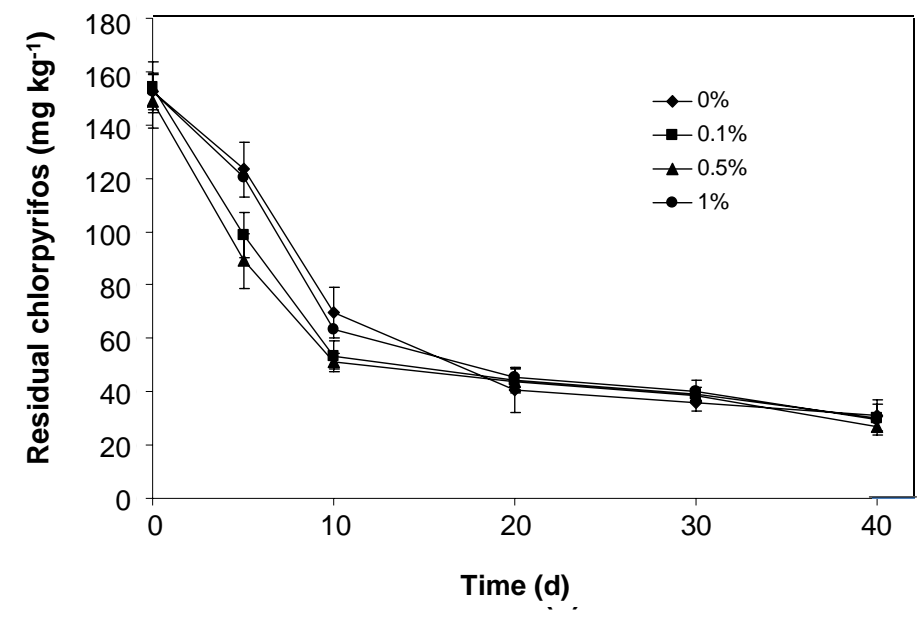

Figure 1. Chlorpyrifos (160 mg kg-1) degradation in biomix of a biobed with different concentrations of NPK fertilizer. 
Biostimulation of the biomix with low NPK concentration $(0.1 \%$ and $0.5 \%)$ on the chlorpyrifos degradation demonstrated that this one has a significant effect during the first 10 days of incubation. We think that a short and fast biostimulation of some microbial population present in the biomix occurred due to the presence of nutrients added. After this time nutrient necessity of the biomix microorganisms could be supported by the available native concentration of nutrients in the biomix. Besides, the opportunity of co-metabolism was enhanced due to the component of the biomix (straw and peat). After 20 days of incubation, nutrients addition did not improve the degradation of chlorpyrifos, probably due to limitation of available fertilizer or by the use of carbon and energy more usable compounds in the biomix (Williams et al., 1993). Biostimulation can improve the degradation of several pesticides in soil (Silva et al., 2004; de Lipthay et al., 2007). Therefore, assays with other nutrient (macro and micronutrients) resources could be evaluated in the biomix to try to improve the degradation of chlorpyrifos in the biomix during the whole incubation period.

Table 2. Degradation of chlorpyrifos (\%) in the biomix with different concentrations of NPK fertilizer.

\begin{tabular}{lcccc}
\hline & \multicolumn{4}{c}{ NPK (\%) } \\
\hline Time (d) & $\mathbf{0}$ & $\mathbf{0 . 1}$ & $\mathbf{0 . 5}$ & $\mathbf{1 . 0}$ \\
5 & 23 & 46 & 37 & 24 \\
10 & 58 & 68 & 67 & 60 \\
20 & 72 & 73 & 72 & 72 \\
40 & 75 & 75 & 75 & 74 \\
\hline
\end{tabular}

Half-life values for chlorpyrifos in the different studied NPK concentrations are shown in Table 3. As it can be observed, chlorpyrifos degradation in the biomix biostimulated with NPK fertilizer was not modified significantly $(p \leq 0.05)$ showing half-life values between 19 and 24 days. These values are very low compared with values reported in the literature. A halflife value for chlorpyrifos between 43 and 59 days has been reported in studies with biomix of biobeds in Europe (Vischetti et al., 2008; Fogg et al., 2003). The differences in the results may be due to the different characteristics of the soil used in our biomix, which has high organic carbon content $(8.8 \%)$ and acidic $\mathrm{pH}$ (5.9). On the other hand, chlorpyrifos has a half-life between 1 and 200 days, depending on the soil characteristics as soil type, $\mathrm{pH}$, and moisture among others (Racke et al., 1990, Racke et al., 1993, Singh et al., 2003). On the other hand, the Andisol used in this study has a great capacity to adsorb chemical compounds as chlorophenols and chlorpyrifos (Diez et al., 1999; Navia et al., 2003; Cea et al., 2007; Tortella et al., 2010) that decrease the half-life value of this contaminant.

Table 3. Half-life values $\left(\mathrm{t}^{1} / 2\right)$ and Groundwater Ubiquity Score (GUS) index of chlorpyrifos obtained in biomix with different concentrations of NPK.

\begin{tabular}{ccccc}
\hline $\begin{array}{c}\mathbf{N P K} \\
\left(\mathbf{\%} \mathbf{~ w ~ w}^{-\mathbf{1}} \mathbf{)}\right.\end{array}$ & $\begin{array}{c}\mathbf{K} \\
\left.\mathbf{( d}^{-\mathbf{1}}\right)\end{array}$ & $\mathbf{t}_{\mathbf{1 / 2}}$ & $\mathbf{r}^{2}$ & $\mathbf{G U S}$ \\
\hline $\mathbf{0 . 0}$ & 0.04 & 18.9 & 0.89 & 0.03 \\
$\mathbf{0 . 1}$ & 0.03 & 24.4 & 0.91 & 0.04 \\
$\mathbf{0 . 5}$ & 0.03 & 23.9 & 0.95 & 0.04 \\
$\mathbf{1 . 0}$ & 0.03 & 19.9 & 0.92 & 0.03 \\
\hline
\end{tabular}

*Different letters refer to significant differences between mean values $(n=3)$ with Duncan Test $(p \leq 0.05)$. 
The GUS index obtained (Table 3) for chlorpyrifos was similar between treatments and no significant differences $(p \leq 0.05)$ were found. The values were lower than 2.8 , which is a limit value between a leachable and non- leachable compound (Gustavson, 1989). This indicates that this compound has a high probability of being retained in the biomix, thereby reducing its lixiviation potential.

Figure 2 shows TCP accumulation in the biomix amended with NPK fertilizer. A clear trend in the TCP accumulation was observed when fertilizer concentration increased in the biomix. Indeed, the highest TCP level was found in the biomix containing $1.0 \%$ of NPK and the lowest TCP level was found in the biomix without fertilizer. TCP is a main metabolite produced during chlorpyrifos degradation and it is an undesirable compound due to its chemical properties. TCP has higher water solubility, lower adsorption coefficient $\left(\mathrm{K}_{\mathrm{oc}}\right)$, higher GUS index and higher half-life value than chlorpyrifos. We assume that the fertilizer added to the biomix can have a stimulatory effect on microbial populations different from TCP-degrading microorganism. Moreover, NPK addition could result in an imbalance of elements, and competition for nutrients within the microbial communities may limit the overall microbial growth and slow contaminant degradation (Biddlestone et al., 1987). The results indicate that the addition of fertilizer as an easily usable nutrient resource in the biomix may affect the adaptation of microorganism to use and to degrade TCP. Similar results were reported by Coppola et al. (2007), where a significant TCP accumulation was observed in the mixtures of biobeds with low content of straw and amended with urban and garden compost. In addition, Castillo et al. (2008) reported that high nitrogen or no lignin content in the biomix may not support an adequate microbial activity for the degradation of pesticides or their metabolites.

\section{Biological activities in the biomix}

The most widely adopted method to estimate microbial activity in soil amended with organic residues and to estimate the effect of stress by the presence of xenobiotics is the hydrolysis of fluorescein diacetate (FDA) (Gaspar et al., 2001; Sanchéz-Monedero et al., 2008)

During the incubation time, it was observed that FDA hydrolysis increased by the addition of different doses of NPK fertilizer up to $0.5 \%$ (Figure 3 ). The highest FDA values were found in the biomix containing $0.1 \%\left(11 \mu \mathrm{g} \mathrm{g}^{-1} \mathrm{~h}^{-1}\right)$ at 20 days of incubation and $0.5 \%\left(9 \mu \mathrm{g} \mathrm{g}^{-1}\right.$ $\mathrm{h}^{-1}$ ) at 30 days of incubation. The lowest FDA values were found in the biomix containing $1 \%$ of NPK being lower than values obtained in the control biomix $(0 \%$ NPK). In a previous work, we found that chlorpyrifos in the same concentration used in this study caused an initial decreasing in FDA activity (Tortella et al., 2010). According to our results, the global microbial activity, quantified through FDA activity, was stimulated by the presence of NPK, except when $1 \%$ of NPK was added.

The NPK addition to the biomix in all used concentrations increased the ligninolytic activity in the biomix compared with the biomix without fertilizer (Figure 4). The highest values of ligninolytic activity were obtained when $0.1 \%$ of NPK fertilizer was added. Ligninolytic enzyme activity (LiP, MnP and laccase) is used to estimate the activity of lignin-degrading fungi (peroxidases and phenoloxidases) from straw solid substrate (Castillo et al., 1997). In some works, ligninolytic activity has been correlated to the 


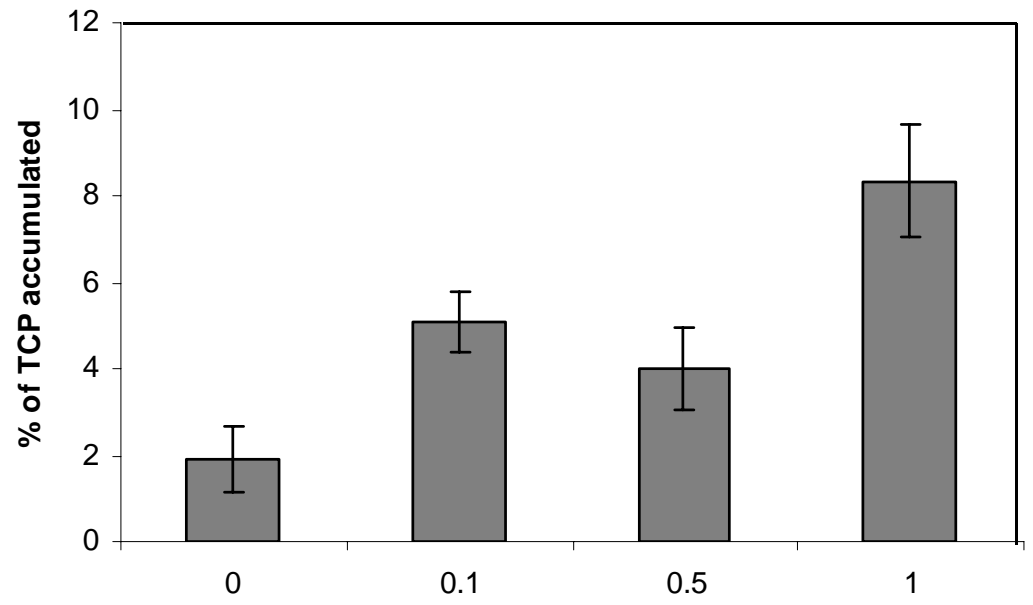

Figure 2. Percentage of TCP (3,5,6-trichloro-2-pyridinol) accumulation with respect to initial concentration of chlorpyrifos $\left(160 \mathrm{mg} \mathrm{kg}^{-1}\right)$ in biomix of a biobed biostimulated with different concentrations of NPK fertilizer after 40 days of incubation.

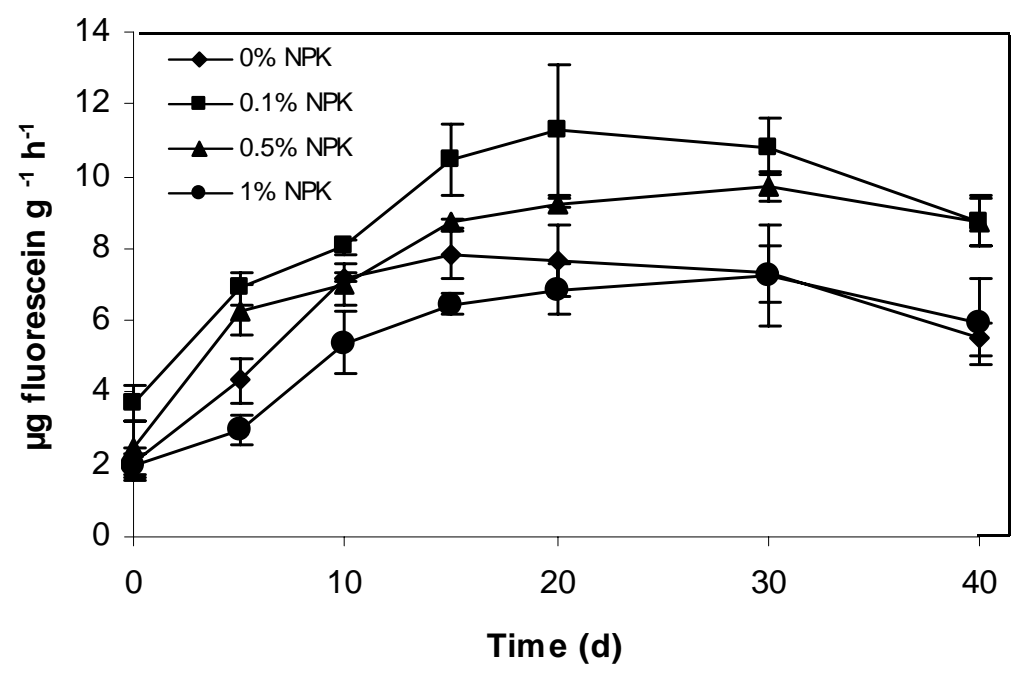

Figure 3. FDA activity in biomix of biobed biostimulated with different concentrations of NPK fertilizer.

degradation of several pesticides, such as isoproturon (Castillo and Torstensson, 2007; Von Wirén-Lehr et al., 2001), chlorpyrifos and TCP (Coppola et al., 2007; Pizzul et al., 2009).
The increment in chlorpyrifos degradation and in biological activities with the addition of NPK fertilizer until 20 days of incubation is associated with half-life values obtained for this pesticide (aprox. 
21 days). The major activity in the biomix due to NPK nutrients probably favored degradation of other lignocellulosic materials in the biomix and not only chlorpyrifos and TCP. No information is provided by the literature in relation to the effects of nutrients in the pesticide degradation in biobed system. It has been reported that ligninolytic activity, although being an important biological process in biomix (Castillo et al., 2008) may not be the only biological activity that governs the processes of pesticide dissipation.
Monitoring the FDA and ligninolytic activity in the biomix of biobeds is only one/an approach to the effects of pesticides on biological activity, since biodegradation of pesticides in the biomix or soil is a series of physical, chemical and biological interactions. Moreover, it has been demonstrated that several enzymes can act in pesticide degradation in soil, such as phosphatases (Hasan, 1999), hydrolases and carboxylesterases (Lan et al., 2005).

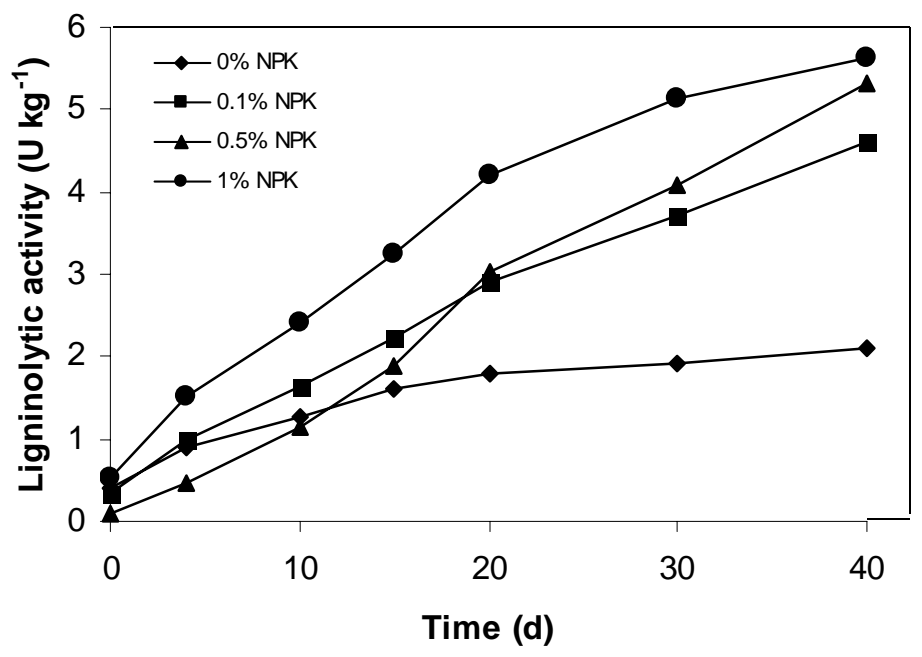

Figure 4. Accumulated ligninolytic activity in biomix of biobed biostimulated with different concentration of NPK fertilizer.

\section{Microbial community analyses}

The effect of NPK application after 15 days of incubation on microbial community modifications were assessed with DGGE and classified by hierarchichal cluster analysis (HCA) (Figure 5). DGGE profiles demonstrated that increments in NPK fertilizing stimulated some bacterial strains $\left(\mathrm{N}^{\circ} 3\right.$, $10,11,12,15,18,19,20,21,22$ and 24). The sample treated with $1.0 \%$ NPK included a higher number of stimulated bacterial strains that were not present in control and sample treated with $0.1 \%$ fertilizer. On the other hand, 
combined treatments with lower amounts of NPK $(0 \%$ and $0.1 \%)$ and chlorpyrifos showed no significant modifications in their microbial community profiles, as compared with the same NPK treatments without chlorpyrifos. However, samples with highest NPK doses plus chlorpyrifos displayed a reduction of bacterial strains $\mathrm{N}^{\mathrm{o}} 11$ and $\mathrm{N}^{\mathrm{o}} 12$. HCA shows that biostimulation with different NPK fertilizing conditions modified the structure of bacterial communities. Furthermore, HCA allowed the classification of different treatments in three clusters into the dendrogram. The first group included the controls $(0 \%)$ and treatments with $0.1 \%$ of NPK fertilization that were also enclosed in two subgroups of samples treated with and without chlorpyrifos. A second group consisted of samples treated only with $0.5 \%$ and $1.0 \%$ NPK supply. The third group included samples that were treated with combined conditions of high NPK doses $(0.5 \%$ and $1.0 \%)$ and chlorpyrifos that displayed a? significant structural difference in their populations as compared with the samples described before.
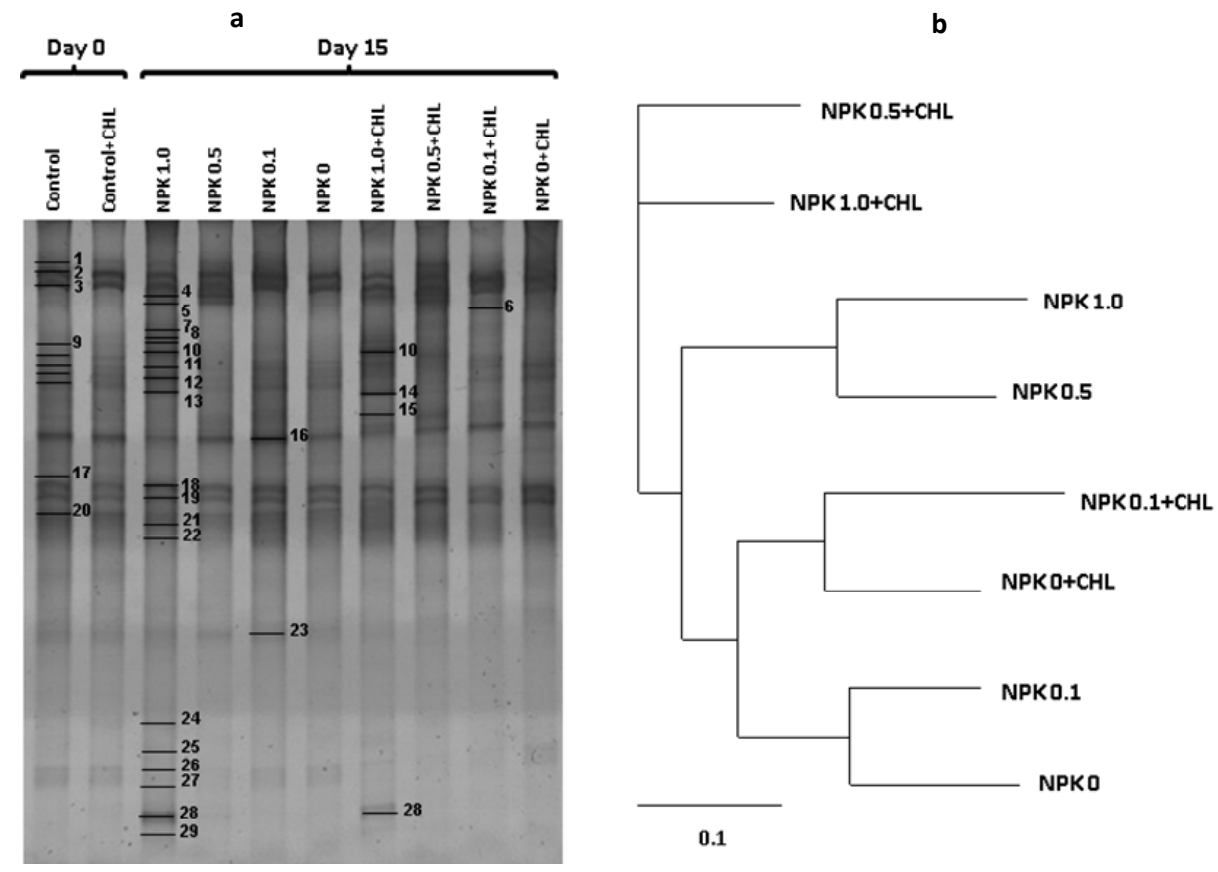

Figure 5. The DGGE banding pattern (a) and clustering representation (b) of the bacterial 16S rRNA genes amplified with the primers sets EUBf933- GC EUBr1387.

\section{CONCLUSIONS}

The results of this study indicate that the addition of nutrients (NPK) up to $0.5 \%$, increased chlorpyrifos degradation during the first days of incubation and concomitant with an increase of the biological activity in the biomix. On the other hand, high NPK doses (0.5 and $1.0 \%$ ) and chlorpyrifos caused significant 
modifications in the bacterial communities that could be associated with the observed TCP $(3,5$, 6-trichloro-2pyrinidol) increment. Moreover, combined treatments with lower amounts of NPK ( 0 and $0.1 \%$ ) and chlorpyrifos did not show any significant modifications in the microbial community in the biomix. Finally, it is necessary to study more details about the effect of nutrients addition in the increase of TCP accumulation in the biomix in long term assays.

\section{ACKNOWLEDGMENTS}

This study was financed by Fondecyt project $\mathrm{N}^{\mathrm{o}}$. 3090049 and partially financed by Fondecyt project $N^{\circ} 1090678$.

\section{REFERENCES}

Biddleston, A.J., Gray, K., Day, C.A. 1987. Composting and straw decomposition. In "environmental biotechnology"(C.F. Foster and D.A Wase, Eds) pp. 135-175. Wiley, New York.

Castillo M.D., Torstensson, L. 2007. Effect of biobed composition moisture, and temperature on the degradation of pesticides. J. Agric. Food Chem. 55, 5725 -5733.

Castillo, M.d.P. Stenström J., Ander. P. 1994. Determination of manganese peroxidase activity with 3-methyl-2- benzothiazolinone hydrasone and 3-(dimethylamino) benzoic acid. Anal. Biochem. 218, 399-404.

Castillo, M.d.P., Ander, P., Stenström, J. 1997. Lignin and manganese peroxidase activity in extracts from straw solid substrate fermentations. Biotech. Techniq. 111, 701-706.

Castillo, MD., Torstensson L., Stenström. J. 2008. Biobeds for environmental protection from pesticide use a review. J. Agric. Food Chem. 56, 6206-6219.

Cea, M., Seaman, J.C., Jara, A.A., Fuentes, B., Mora, M.L., Diez, M.C. 2007. Adsorption behavior of 2,4-dichlorophenol and pentachlorophenol in an allophanic soil Chemosphere 67, 354-1360.

Cea, M., Jorquera, M., Rubilar, O., Tortella, G., Diez, M.C. 2010. Bioremediation of soil contaminated with pentachlorophenol by Anthracophyllum discolor and its effect on soil microbial community. J. Hazar. Mater. 181,315323.

Chu, X.Q., Fang, H., Pan, X.D., Wang, X., Shan, M., Feng B., Yu, YL. 2008. Degradation of chlorpyrifos alone and in combination with chlorothalonil and their effects on soil microbial populations. J. Environ. Sci. 20, 464-469.

Coppola, L., Castillo, M.d.P., Monaci, E., Vischetti, C. 2007. Adaptation of the biobed composition for chlorpyrifos degradation to southern Europe conditions. J. Agric. Food Chem. 55, 396-401.

de Lipthay, R., Sorensen S.R., Aamand, J. 2007. Effect of herbicide concentration and organic and inorganic nutrient amendment on the mineralization of mecoprop, 2,4-D and 2,4,5-T in soil and aquifer samples. Environ. Pollut. 148, 83-93.

Diez, M.C., Mora, M.L., Videla S. 1999. Adsorption of phenolic compounds and color from bleached kraft mill effluent using allophanic compounds. Water Res. 33, 125-130.

Fogg, P., Boxall, A.B.A., Walker, A. 2003. Degradation of pesticides in biobeds, the effect of concentration and pesticide mixtures. J. Agric. Food Chem. 51, 53445349.

García-Blanco, S.A.D., venosa, M., Suidan, T., Lee, K., Cobanli, S., Haines, J.R. 2007. Biostimulation for the treatment $o$ fan oil contaminated coastal salt march. R.L. Crawford (Ed.). Biodegradation 18, 1-15.

Gaspar, M., Cabello, M., Pollero, R., Aon, M. 2001. Fluorescein diacetate hydrolysis as a measure of fungal biomass in soil. Current Microbial. 42, 339-344.

Gustavson, D.I. 1989. Groundwater ubiquity score: a simple method for assessing pesticide leachability. Environ. Toxicol. Chem. 8, 339357.

Hasan, H. 1999. Fungal utilization of organophosphate pesticides and their degradation by Aspergillus flavus and A. sydowii in soil. Fol. Microbiol. 44, 77-84. 
Lan, W.S., Cong, J., Jiang, H., Gu, B.G., Qiao, C.L. 2005. Biodegradation of pesticide pollutants by two kinds of enzymes coexpressed in genetically engineered bacteria. Bull. Environ. Contamin. Toxicol. 75, 335-342.

Margesin, R., Schinner, F. 2001. Bioremediation (natural and biostimulation) of diesel-oil-contaminated soil in an alpine glacier skiing area. Appl. Environ. Microbiol. 67, 3127 3133

McGhee, I., Burns, R.G. 1995. Biodegradation of 2,4-dichlorophenoxyacetic acid (2,4-D) and 2methyl-4-chlorophenoxyacetic acid (MCPA) in contaminated soil. Appl. Soil Ecol. 2, 143-154.

Navia, R., Levet, L., Mora, M.L., Vidal, G., Diez, M.C. 2003. Allophanic soil adsorption system as a bleached Kraft mill effluent posttreatment. Water, Air and Soil Pollution 148, 323-333.

Phillips, T.A., Summerfelt, R.C., Wu, J., Laird D,A. 2003. Toxicity of chlorpyrifos adsorbed on humic colloids to larval walleye (Stizostedion vitreum). Arch. Environ. Contam. Toxicol. 45, 258-263.

Pizzul, L., Castillo, M., del P. Stenström, J. 2009. Degradation of glyphosate and other pesticides by ligninolytic enzymes. Biodegradation 20, 751-759.

Racke, K.D. 1993. Environmental fate of chlorpyrifos. Rev. Environ. Contam. Toxicol. $131,1-154$.

Racke, K.D., Laskowski, A., Schultz, M.R. 1990. Resistance of chlorpyrifos to enhanced biodegradation in soil. J. Agric. Food Chem. 38, 1430-1436

Racke, KD., Steele, KP., Yoder, R.N., Dick WA., Avidov, E. 1996. Factors affecting the hydrolytic degradation of chlorpyrifos in soil. J. Agric. Food Chem. 44, 1582-1592.

Sánchez-Monedero, M., Mondini, C., Cayuela, M.L., Roig, A., Contin M., Nobili. M. 2008. Fluorescein diacetate hydrolysis, respiration and microbial biomass in freshly amended soils. Biol. Fertil. Soils 44, 885-890.
Schnürer, J., Rosswall, T. 1982. Fluorescein diacetate hydrolysis as a measure of total microbial activity in soil and litter. Appl. Environ. Microbiol. 6, 256-1261.

Silva, E., Fialho, A., Sa-Correia, I., Burns, R. Shaw, L. 2004. Combined bioaugmentation and biostimulation to clean up soil contaminated with high concentrations of atrazine. Environ. Sci. Technol. 38, 632-637.

Singh, B.K., Walker, A., Morgan, A.J.W., Wright, D.J. 2003. Effects of soil $\mathrm{pH}$ on the biodegradation of chlorpyrifos and isolation of a chlorpyrifos-degrading bacterium. Appl. Environ. Microbiol. 69, 5198-5206.

Torstensson, L., Castillo, M.d.P. 1997. Use of biobeds in Sweden to minimize environmental spillages from agricultural spraying equipment. Pestic. Outlook 8, 24-27.

Tortella, G.R., Rubilar, O., Avendaño, M., Cea, M., Diez, M.C. 2010. Chlorpyrifos dissipation in a biomix of biobed systems amended with an allophanic top soil. (Submitted J. Hazard. Mat. Hazmat-D-10-04145).

Vischetti, C., Monaci, E., Cardinali, A., Casucci, C., Perucci, P. 2008. The effect of initial concentration, co-application and repeated applications on pesticide degradation in a biobed mixture, Chemosphere. 72, 1739-1743.

Von Wirén-Lehr, S., Castillo, M.d.P., Torstensson L., Scheunert, I. 2001. Degradation of isoproturon in biobeds. Biol. Fert. Soils 33, 535-540.

Williams, R.T., Keehan, K.R. 1993. Hazardous and Industrial Waste Composting. In: Science and Engineering of Composting, Hoitink, H.A.J. and H.M. Keener (Eds.). Renaissance Press, Worthington, $\mathrm{OH}$., pp, 363-382.

Wu, J., Laird, D.A. 2004. Interactions of chlorpyrifos with colloidal materials in aqueous systems. J. Environ. Qual. 33, 1765-1770. 